\title{
MISE AU POINT \\ SUR LA SÉPARATION, L'IDENTIFICATION \\ ET LE DOSAGE DES PROTÉINES DU LAIT DE VACHE A L'EXCLUSION DES CASÉINES ${ }^{(1)}$
}

\author{
par \\ J. GARNIER \\ Station centrale de Recherches laitières \\ et de Technologie des Produits animaux, \\ Centre national de Recherches zootechniques, Jouy-en-Josas (S.-O.)
}

\section{Introduction}

Parmi les produits d'origine biologique, le lait représente une source abondante de protéines, facile à recueillir et très largement utilisée par l'homme pour son alimentation. Pour le nouveau-né, il joue un rôle primordial et représente le dernier contact de ce nouveau-né avec sa mère.

C'est certainement le lait de vache qui a été le plus étudié du fait de la facilité avec laquelle il peut être récolté en quantité importante.

On attribue généralement aux protéines du lait deux origines différentes, d'après leur lieu de synthèse : ou bien elles sont synthétisées par le tissu de la glande mammaire elle-même, ou bien elles proviennent $d u$ sang par simple filtration à partir du courant sanguin irriguant la mamelle. Ces deux origines possibles des protéines du lait ont été étudiées par analyse immunologique (d'après le procédé employé notamment par Von Gugler, Bein et Von Muralt (1959) ou en déterminant la vitesse d'incorporation du ${ }^{14} \mathrm{C}$ dans les différentes protéines (c'est la méthode adoptée par Larson et Gillespie (1957). Les analyses immuno-électrophorétiques de Von Gugler, Bein et Von Muralt (1959) et de Hanson (1959) ont permis de dénombrer dans le lait de vache 15 à 21 protéines antigéniques. Parmi celles-ci 7 à 8 protéines sont rencontrées exclusivement dans le lait et sont par conséquent synthétisées dans la glande mammaire. En accord avec les travaux de Larson et Gillespie (1957), ce groupe comprend la $\beta$-lactoglobuline, l' $\alpha$ lactalbumine, la protéine rouge et la majeure partie des caséines en particulier la caséine $\alpha$ et la caséine $\beta$. Les autres protéines du

(1) Ann. Biol. anim. Biophys., 1964, 4 (2), 163-187. 
lait (7 d'après Von Gugler, Bein et Von Muralt (1959) à 14 d'après Hanson (1959)) sont, au point de vue immunologique, identiques à celles du sang et passent dans le lait par simple filtration. Tel est le cas en particulier de la sérum albumine et des immunoglobulines.

La séparation et l'identification des différents constituants protéiques du lait ont donné lieu à un nombre considérable de travaux dont nous ne ferons pas l'historique, nous contentant simplement de rapporter les procédés de séparation utilisés actuellement. Certains de ces constituants peuvent faire l'objet d'un dosage spécifique mais ils ne représentent qu'une minorité. Le plus souvent, le dosage d'un groupe de constituants est seul possible (par exemple dosages des caséines, des globulines, des protéoses peptones).

Bien que la caséine figure parmi les préparations protéiques les plus anciennement mises au point (Mülder (1838) l'obtenait par addition de vinaigre à du lait puis redissolution à l'aide de salpêtre) son étude ultérieure a révélé une grande complexité en raison d'interactions très fortes entre ses divers constituants dont le nombre a été évalué à 21 par Wake et Baldwin (1961).

Comme la séparation et l'identification des caséines est encore à l'heure actuelle une question complexe, controversée et en pleine évolution, nous avons limité notre étude aux autres protéines du lait, appelées protéines du lactosérum ou encore protéines solubles. Nous pouvons les définir comme les protéines restant en solution

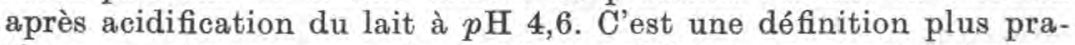
tique que rigoureuse car les caséines précipitées peuvent entraîner par adsorption une partie des protéines du lactosérum, comme c'est le cas de la protéine rouge et de la lactolline (Groves, 1960 et Groves et al., 1963). De plus, il existe d'autres procédés pour éliminer les caséines : précipitation par les sels neutres, précipitation du paracaséinate de calcium après action de la présure ou simplement centrifugation à $45000 \mathrm{~g}$ des micelles de caséines selon Mocquot, Alais et Chevalier (1954) ou Von Hippel et Waugh (1955). Ces procédés ne conduisent pas tous au même résultat. En effet Brunner et Thompson (1961) ont montré que la fraction de Weinstein, obtenue après élimination des caséines par emprésurage, contenait une part importante des produits de scission résultant de l'attaque des caséines par la présure.

Les protéines du lactosérum représentent 18 à 21 p. 100 des protéines totales du lait de vache, soit environ $5,5 \mathrm{~g}$ à $6,5 \mathrm{~g} /$ litre d'après les déterminations faites par Rolleri, Larson et Touchberry (1956) en comparant plusieurs races laitières. D'après les analyses électrophorétiques de McMeekin (1954) et, fig 1, de Larson et Rolleri (1955), 80 p. 100 de ces protéines sont constituées par la $\beta$-lactoglobuline, l' $\alpha$-lactalbumine, la sérum albumine et les immunoglobulines. Les trois premières de ces protéines ont été préparées 
à l'état cristallisé. Nous avons porté dans le tableau 1 l'importance relative de chacun des constituants d'après Larson et Rolleri (1955) et d'après les dosages par voie chimique d'Aschaffenburg

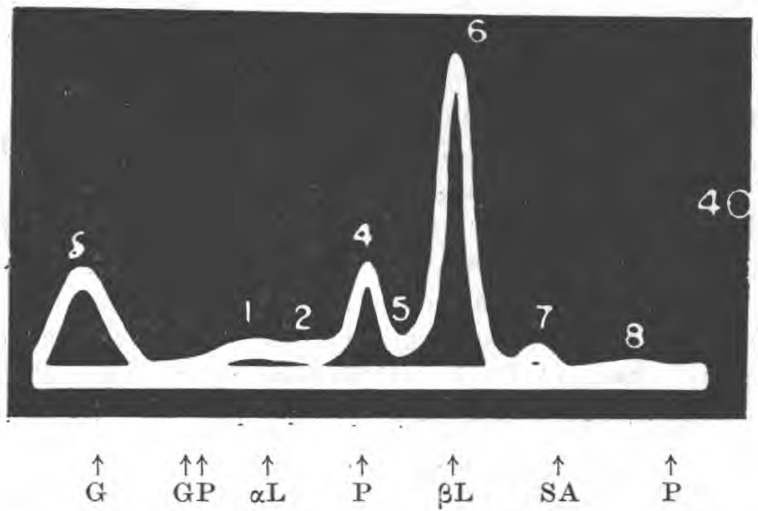

Fig. 1. - Electrophorèse selon Tiselius du lactosérum du lait de vache (LARson et Rolleri (1955)) en tampon véronal $p \mathrm{H} 8,6, \Gamma / 2=0,1$. Branche ascendante. Concentration en protéines $1,9 \%$.

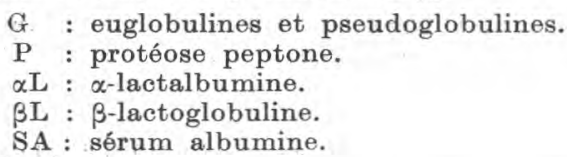

et Drewry (1959). L'écart observé entre ces deux séries de résultats peut provenir : d'une association entre deux constituants ou d'une migration identique de deux constituants par électrophorèse ou encore dans la méthode chimique employée par Aschaffenburg et Drewry (1959) d'une séparation incomplète et du caractère arbitraire du coefficient servant à multiplier la teneur en azote pour obtenir la teneur en protéines. Dans l'établissement de ces pourcentages il n'est pas tenu compte des protéines mineures du lactosérum comme la protéine rouge, les protéines de la membrane des globules gras et divers enzymes qui constituent au total environ 1 à 2 p. 100 . Parmi ces protéines en faible proportion, certaines peuvent jouer un rôle important, par exemple en inhibant la croissance de certains microorganismes dans le lait (lactoperoxydase d'après Wright et Tramer, 1958) ou en permettant une vérification du traitement. du lait par la chaleur (phosphatase alcaline).

Nous avons classé les protéines du lactosérum en quatre groupes, la division entre les deux premiers est fondée sur le fractionnement des protéines du lait par les sels neutres, fractionnement le plus anciennement utilisé. Nous avons ensuite réuni dans un troisième groupe les protéoses peptones et dans un quatrième les constituants protéiques mineurs du lait. 
Les albumines correspondent aux protéines solubles à $p H$ neutre en solution demi saturée en sulfate d'ammonium ou en solution saturée de sulfate de magnésium. On les distinguait autrefois sous le nom de lactalbumine et Pedersen (1936) avait décelé par ultracentrifugation les constituants $\alpha, \beta$ et $\gamma$. Le constituant $\alpha$ a été appelé $\alpha$-lactalbumine, le constituant $\beta$ a été appelé par Pedersen lactoglobuline en raison de sa faible solubilité en solution saline diluée au point isoélectrique et c'est Cannan, Palmer et Kibrick (1942) qui proposèrent de l'appeler $\beta$-lactoglobuline. Le troisième constituant est la sérum albumine identique à celle du sang. Aschaffenburg et Drewry (1957), distinguent, en plus, deux autres constituants mineurs qui en électrophorèse, ne migrent ni avec l' $\alpha$-lactalbumine, ni avec la sérum albumine. Ceci explique les teneurs plus faibles en albumines autres que la $\beta$-lactoglobuline obtenues par Larson et Rolleri (1955) comparées à celles d'Aschaffenburg et Drewry (1959) (tabl. 1).

\section{TABLEAU I}

PRINCIPAUX CONSTITUANTS PROTÉIQUES DU LACTOSÉRUM DU LAIT DE VACHE NORMAL

\begin{tabular}{|c|c|c|c|c|}
\hline & \multicolumn{2}{|c|}{$\begin{array}{l}\text { D'après Larson } \\
\text { et Rolleri ( } 1955)\end{array}$} & \multicolumn{2}{|c|}{$\begin{array}{c}\text { D'après Aschaffenburg } \\
\text { et Drewry }(1959)\end{array}$} \\
\hline & $\%(1)$ & g/litre de lait (2) & $\%(1)$ & g/litre de lait (2) \\
\hline Immuno-globulines & 13 & $0,7-0,8$ & 10,7 & $0,6-0,7$ \\
\hline Albumines & 68,1 & & 79,7 & \\
\hline$\beta$-lactoglobuline ..... & 43,7 & $2,4-2,9$ & 49,6 & $2,7-3,2$ \\
\hline$\alpha$-lactalbumine ...... & 19,7 & $1,1-1,3$ & & \\
\hline Sérum albumine .... & 4,7 & $0,25-0,3$ & 30,1 & $1,7-2,0$ \\
\hline Autres albumines ... & 0 & - & ( & constituants) \\
\hline Protéoses peptones & 18,9 & & 9,6 & $0,5-0,6$ \\
\hline & & & $(6$ & constituants) \\
\hline Constituant $3 \ldots \ldots$ & 4,6 & $0,25-0,3$ & & \\
\hline Constituant $5 \quad \ldots \ldots$ & 8,6 & $0,45-0,55$ & & \\
\hline Constituant $8 \ldots \ldots$ & 5,7 & $0,3-0,4$ & & \\
\hline
\end{tabular}

(1) \% des protéines du lactosérum.

(2) g/litre de lait calculés d'après une teneur en protéines du lactosérum variant entre 5,5 et $6,5 \mathrm{~g} /$ litre.

Les globulines, appelées aussi lactoglobulines, sont insolubles à $p \mathrm{H}$ neutre en solution de sulfate d'ammonium à demi saturation ou dans le sulfate de magnésium saturé. Elles ont été divisées par Crowther et Raistrick (1916) en euglobulines (insolubles dans l'eau 
distillée au point isoélectrique) et pseudoglobulines (solubles dans les mêmes conditions). Cette fraction globuline est essentiellement constituée par les immuno-globulines.

Enfin les protéoses peptones sont constituées par un ensemble mal connu de glycoprotéines solubles dans l'acide trichloracétique à 4 p. 100 .

Pour chacun des constituants nous indiquerons les méthodes de séparation et nous donnerons très ragidement quelques propriétés caractéristiques permettant l'identification. Pour certains constituants nous étudierons les méthodes de dosage proposées.

\section{I. - Les albumines}

\section{A. - La $\beta$-lactoglobuline}

La $\beta$-lactoglobuline est un constituant protéique majeur des protéines du lactosérum (tabl. 1) et elle a donné lieu à de nombreux travaux dont Tilley (1960) a fait une revue extensive. C'est une des plus rares protéines du lait, avec l' $\alpha$-lactalbumine, préparée à l'état cristallisé qu'il soit possible de doser spécifiquement. Elle est synthétisée par l'organisme sous deux formes au moins A et B

TABLEAU 2

MÉTHODES DE PRÉPARATION DE LA ß-LACTOGLOBULINE DU LAIT DE VACHE

10) Selon Cecil et Ogston (1949).

Lait écrémé

Filtrat Précipité : Caséines, Immuno-globulines et un peu de $\beta$-lactoglobuline $\downarrow+\left(\mathrm{NH}_{4}\right)_{2} \mathrm{SO}_{4}$ à $82 \%$ de saturation $(3,2 \mathrm{M})$ Fillrat Précipité

$$
\underbrace{\begin{array}{l}
+ \text { NaCl } 1 \mathrm{M} \\
\text { dialyse } 24 \mathrm{~h} \\
\text { contre l'eau }
\end{array}}_{\text {Filtrat Précipité }}
$$

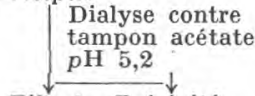

Filtrat Précipité

Dialyse contre
l'eau

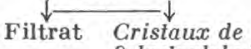

$\beta$-lactoglobuline

Recristallisation à partir du

tampon acétate $p \mathrm{H} 5,2$ ou $\mathrm{NaCl}$ $2^{\circ}$ ) Selon Aschaffenburg et Drewry (1957)a

Lait entier

$\theta=40^{\circ} \mathrm{C}+\mathrm{Na}_{2} \mathrm{SO}_{4}(20 \mathrm{~g} / 100 \mathrm{ml})$ refroidir à $25^{\circ} \mathrm{C}$

Filtrat Précipité : caséines, globulines,

$$
\begin{array}{|l}
\text { protéoses peptones, graisse } \\
+1 \mathrm{ml} \mathrm{HCl} \text { concentré } \\
\text { pour } 100 \mathrm{ml}
\end{array}
$$

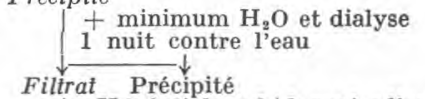

Filitrat Précipité

pH 5,8 dialyse $24 \mathrm{~h}$ contre l'eau pH 5,2 avec $\mathrm{HCl}$ dilué Filtrat Cristaux de 
contrôlées par un seul gène d'après Aschaffenburg et Dre wry (1957) $b$. L'individu hétérozygote produit un mélange de $\beta$-lactoglobuline $A$ et $B$ (environ 60 p. 100 de $A$ et 40 p. 100 de B d'après Aschaffenburg et Drewry (1955). La $\beta$-lactoglobuline A diffère en particulier de la $\beta$-lactoglobuline $B$ par la présence d'un acide aspartique et d'une valine à la place d'un glycocolle et d'une alanine d'après Piez et al. (1961) ce qui lui confère une plus grande mobilité électrophorétique et permet de les séparer l'une de l'autre (Aschaffenburg et Drewry 1955, ; Piez et al. 1961). Une $\beta$-lactoglobuline C a été récemment signalée (Bell, 1962).

\section{a) Séparation}

La méthode de préparation de Palmer (1934) modifiée plus tard par Cecil et Ogston (1949) a été souvent utilisée. Une méthode plus simple a été proposée par Aschaffenburg et Drewry (1957) $a$. Les deux techniques ont été schématisées dans le tableau 2 d'après Tilley (1960). Si la méthode de Cecil et Ogston est plus longue et d'un rendement moindre, elle présente l'avantage de ne pas nécessiter l'addition d'acide ou de base qui risque d'entraîner une dénaturation partielle d'après Pedersen (1936) $b$ et Linderstrom Lang et Jacobsen (1941). La préparation de Cecil et Ogston est immunologiquement homogène d'après Von Gugler, Bein et Von Muralt (1959).

D'après Aschaffenburg et Drewry (1957)a la quantité de $\beta$ lactoglobuline cristallisée obtenue est de 1,3 à $1,5 \mathrm{~g} /$ litre, quantité qu'il convient de comparer à la teneur totale du lait en $\beta$-lactoglobuline, soit 2,4 à 3,2 g/litre (d'après Jenness et al. (1956), Rolleri, Larson et Touchberry (1956) et Aschaffenburg et Drewry (1959)).

Pour préparer la $\beta$-lactoglobuline A ou B il suffit d'effectuer la préparation à partir du lait provenant d'individus homozygotes $\mathbf{A}$ ou B. Piez et al. (1961) ont séparé les deux $\beta$-lactoglobulines à partir d'un mélange des deux, par chromatographie sur D.E.A.E.cellulose.

\section{b) Identification}

La $\beta$-lactoglobuline fut la première protéine du lait à être préparée à l'état cristallisé par Palmer (1934). Le mélange de $\beta$-lactoglobuline $\mathrm{A}$ et $\mathrm{B}$ cristallise dans le système orthorhombique cependant que la $\beta$-lactoglobuline B seule, cristallise spontanément dans le système monoclinique et l'ensemencement en cristaux orthorhombiques est nécessaire pour qu'elle cristallise dans ce système. Outre la propriété de cristalliser facilement la $\beta$-lactoglobuline a été identifiée par sa mobilité électrophorétique en phase liquide $(\mu=-5,1$ en tampon véronal $p \mathrm{H} 8,4 \Gamma / 2=0,1$, d'après McMeekin (1954)) et elle correspond au constituant $n^{\circ} 6$ de Larson et Rolleri (1955). Elle correspond également au constituant $\beta$ observé par Pedersen (1936) $a$ dont la constante de sédimen- 
tation $\mathrm{S}^{20}$ est égale à 2,8 à $p \mathrm{H} 5$ d'après Ogston et Tombs (1957). Par électrophorèse sur papier à température ordinaire en tampon véronal $p \mathrm{H}$ 8,6 Aschaffenburg et Drewry (1955) séparent les $\beta$ lactoglobulines A et B ainsi que Piez et al. (1961) par chromatographie sur D.E.A.E.-cellulose à $p \mathrm{H} 5,8$ à $5^{\circ}$ C. Le coefficient d'extinction de la $\beta$-lactoglobuline $\mathrm{A}$ ou $\mathrm{B}$ à $278 \mathrm{~m} \mu$ en tampon acétate $p \mathrm{H} 5,3 \mathrm{\Gamma} / 2=0,1$ est $\mathrm{E}^{\frac{1 \mathrm{mg} / \mathrm{ml}}{1 \mathrm{~cm}}}=0,96$ d'après Townend et al. (1960).

\section{c) Dosage}

Nous décrirons deux méthodes, l'une chimique l'autre immunochimique, toutes deux dosant les 2 formes A et B de 3 -lactoglobuline.

\section{1) Méthode de dosage chimique}

Elle est due essentiellement à Aschaffenburg et Drewry (1959) et consiste à précipiter au cours d'une première phase toutes les protéines du lait, à l'exception des albumines, en ajoutant $20 \pm 1 \mathrm{~g}$ de sulfate de sodium anhydre à $100 \mathrm{ml}$ de lait. Le filtrat est amené ensuite à $p \mathrm{H} 2$ par addition d'acide chlorhydrique, seules la $\beta$ lactoglobuline et les substances azotées non protéiques restent en solution (Aschaffenburg et Drewry (1957)a. De l'azote du filtrat (dosé par Kjeldahl), on déduit l'azote non protéique (azote soluble après précipitation des protéines du lait par l'acide trichloracétique à 12 p. 100 de concentration finale). Les résultats obtenus (tabl. 1) sont très semblables sinon identiques à ceux de Larson et Gillespie (1957) obtenus en mesurant la surface du pic observé au cours de l'électrophorèse des protéines solubles selon le procédé de Tiselius.

\section{2) Méthode de dosage immunochimique}

Elle a été mise au point par Larson et Twarog (1961) d'après la technique d'Oudin (1948). Elle consiste à superposer à une couche de gélose mélangée à un sérum anti- $\beta$-lactoglobuline, une solution contenant 15 à $70 \mathrm{\gamma} / \mathrm{ml}$ de $\beta$-lactoglobuline dans un petit tube de $2 \mathrm{~mm}$ de diamètre intérieur et d'environ $10 \mathrm{~cm}$ de long. La solution de $\beta$-lactoglobuline diffuse dans la gélose et précipite au contact des anticorps : on mesure au pied à coulisse la distance $\mathrm{D}$ qui sépare l'interface (solution de $\beta$-lactoglobuline et gélose) du front du précipité au bout d'un temps T $(24,48$ ou $72 \mathrm{~h})$. Les auteurs ont montré qu'il y avait une relation linéaire entre le rapport $\mathrm{D} / \sqrt{\mathrm{T}}$ et le logarithme de la concentration en $\beta$-lactoglobuline. Une courbe étalon est tracée à partir de quantités connues de $\beta$-lactoglobuline. La précision, \pm 10 p. 100 , est de l'ordre de celle que l'on obtient pour la mesure des concentrations par la méthode d'électrophorèse selon Tiselius. Elle est moins bonne que la méthode chimique mais cette méthode est très spécifique, très sensible et surtout elle 
permet de doser la $\beta$-lactoglobuline dans des milieux très complexes contenant de nombreuses autres protéines parmi lesquelles la $\beta$-lactoglobuline ne figure que dans la proportion 1/10 000.

Après concentration par lyophilisation il est possible de doser jusqu'à $0,5 \gamma / \mathrm{ml}$ de $\beta$-lactoglobuline mais la précision est moins bonne : \pm 20 p. 100 .

Cette technique a l'inconvénient de dépendre de la préparation d'un anti-sérum, réactif biologique long à préparer et variable à chaque préparation : d'où la nécessité de refaire la courbe étalon pour chaque sérum et même chaque préparation de gélose. Au cours de l'immunisation il faut utiliser un antigène très purifié, Larson et Twarog (1961) ont recristallisé 8 fois la $\beta$-lactoglobuline.

\section{3) Conclusion}

La méthode d'Aschaffenburg et Drewry (1959) nous semble être celle qui s'applique le mieux au lait, car elle est plus précise et plus commode d'emploi. La technique de Larson et Twarog (1961) se montre particulièrement utile lorsque les concentrations en $\beta$-lactoglobuline sont très faibles et que les dosages doivent se faire à partir de milieux complexes tels que par exemple les broyats de culture de tissus mammaires ou encore les fromages, les produits alimentaires à base de poudre de lait, etc.

A divers titres, la $\beta$-lactoglobuline présente des caractéristiques intéressantes. Elle est responsable de la majorité des groupements SH libres qui existent dans le lait. Elle possède en commun avec la sérum albumine la propriété de former des complexes avec de nombreux métaux. La $\beta$-lactoglobuline $A$ se polymérise en dimère et tétramère dans la zone de $p H$ 3,7 à 5,3 alors que la $\beta$-lactoglobuline $B$ reste sous forme monomère ou dimère. Les deux formes de $\beta$-lactoglobuline peuvent s'associer entre elles (Timasheff et Townend $1961 a$ ) et à $p \mathrm{H}<3,7$ se dissocier en deux sous-unités non interchangeables (Timasheff et Townend (1961) $b$ et Townend, Kiddy et Timasheff 1961). En raison de la grande facilité de sa préparation sous forme cristallisée, de nombreux travaux ont été effectués en ce qui concerne l'action des enzymes protéolytiques sur la $\beta$-lactoglobuline ou sa dénaturation par chauffage ou en présence d'urée par exemple.

\section{B. - L' $\alpha$-lactalbumine}

C'est assez récemment que Gordon et Semmett (1953), Gordon, Semmett et Ziegler (1954) publièrent la méthode de préparation de l' $\alpha$-lactalbumine cristallisée, à la suite des travaux de Sørensen et Sørensen (1939). Aussi peu de travaux ont-ils été publiés concernant cette protéine qui représente environ $20 \mathrm{p} .100$ des protéines du lactosérum d'après Larson et Rolleri (1955) (tabl. 1). 


\section{a) Séparation}

Dans le tableau 3 nous avons reporté côte à côte les deux techniques de préparation selon Gordon et al. (1953 et 1954) et d'Aschaffenburg et Drewry (1957)a. Des deux méthodes, celle d'Aschaffenburg et Drewry semble la plus simple et présente l'avantage de conduire à la séparation de la $\beta$-lactoglobuline et de la sérum albumine dans la même suite d'opération.

Dautrevaux (1963) a présenté récemment une autre méthode de préparation permettant d'obtenir avec un bon rendement une préparation purifiée d' $\alpha$-lactalbumine. Cette préparation contient encore comme principale impureté de la $\beta$-lactoglobuline; elle est essentiellement fondée sur un fractionnement par le sulfate d'ammonium, précipitation à $p \mathbf{H}$ acide et filtration finale sur Séphadex.

\section{b) Identification}

L' $\alpha$-lactalbumine correspond au pic $\alpha$ d'ultracentrifugation des protéines du lactosérum d'après Pedersen (1963). Son cœfficient de sédimentation $\mathrm{S}_{20}$ est égale à 1,75 en tampon phosphate $p \mathrm{H} \quad 7,5$ $\Gamma / 2=0,2$. Sa mobilité électrophorétique en tampon véronal $p \mathbf{H}$ 8,5 est de - 4,2 mais, d'après Larson et Jenness (1955), la mobilité est portée à - 3,6 en présence des autres protéines du lactorésum, ce qui permet d'identifier le pic $n^{\circ} 4$ de l'électrophorèse selon Tiselius (cf. fig. 1) à celui de l' $\alpha$-lactalbumine contrairement aux résultats de McMeekin (1954). D'après Aschaffenburg et Drewry (1957)a, l' $\alpha$-lactalbumine cristallise sous trois formes différentes. Gordon et Ziegler (1955) ont étudié sa composition en acides aminés et ont trouvé une forte teneur en tryptophane (7 p. 100) d'où un fort coefficient d'extinction E $1 \underset{1 \mathrm{~cm}}{\mathrm{mg} / \mathrm{ml}}=2,09$ à $280 \mathrm{~m} \mu$ (Lissitzky, Rolland et Lasry (1960). Son pouvoir rotatoire $(\alpha) \frac{25}{\mathrm{D}}=-60 \pm 20$ d'après Gordon et Semmett (1953) ne varie pas entre $p H$ 6,8 et 9,7. Elle présente un minimum de solubilité entre $p H$ 4,1 et 4,8 $\langle 0,2$ p. 100 dans une solution de $\mathrm{NaCl} 0,05$ à $0,1 \mathrm{M}$ ) et ceci la rapproche d'une globuline mais elle est insoluble en solution saline concentrée ( $\mathrm{NaCl} 5$ p. 100) (Gordon et Semmett, 1953).

\section{c) Dosage}

La méthode d'Aschaffenburg et Drewry (1959) ne détermine que la somme : $\alpha$-lactalbumine + sérum albumine + deux constituants mineurs. Seule la mesure de la surface relative du pic observé par électrophorèse de Tiselius permet d'évaluer la concentration en a-lactalbumine en tenant compte de la remarque de Larson et Jenness (1955) concernant l'influence des protéines du lactosérum sur la mobilité de l' $\alpha$-lactalbumine. Aussi la méthode de dosage immunologique mise au point par Larson et Hageman 
TABLEAU 3

MÉTHODES DE PRÉPARATION DE L' $\alpha$-IACTALBUMINE DU LAIT DE VACHE

$1^{\circ}$ ) Selon Gordon, Semmet et Ziegler (1954) $2^{\circ}$ ) Selon Aschaffenburg et Drewhy (1957) $a$

Lait écrémé

$+\mathrm{HCl} \mathrm{N} p \mathrm{H} 4,6$
$\begin{aligned} & + \\ & +\end{aligned}$

$++\mathrm{NH}_{4} \mathrm{OH} \mathrm{N}, p \mathrm{H} 6,0$

$\left(\mathrm{NH}_{4}\right)_{2} \mathrm{SO}_{4} 3,3 \mathrm{M}$

Filtrat Précipité

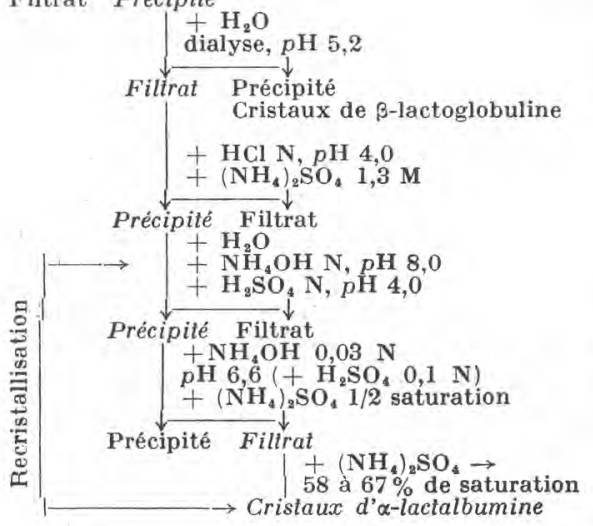

Lait entier

$\theta=40^{\circ} \mathrm{C}+\mathrm{Na}_{2} \mathrm{SO}_{4}(20 \mathrm{~g} / 100 \mathrm{ml})$

Refroidir à $25^{\circ} \mathrm{C}$

Filtrat Précipité : caséines, globulines, protéoses' peptones, graisse

$+1 \mathrm{ml} \mathrm{HCl}$ concentré pour $100 \mathrm{ml}$

Filtrat Précipité

$\beta$-lactoglobuline $\quad+\mathrm{H}_{2} \mathrm{O}$ et $\mathrm{NH}_{4} \mathrm{OH}$

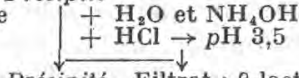

Précipité Filtrat: $\beta$-lactoglobuline

$+\mathrm{NH}_{4} \mathrm{OH}$ dilué

$+\mathrm{HCl} \rightarrow p \mathrm{H} 4,0$ et centrifugation

$+\left(\mathrm{NH}_{4}\right)_{2} \mathrm{SO}_{4} 11,5 \mathrm{~g} / 100 \mathrm{ml}$

Précipité Filtrat : sérum albumine

$+\mathrm{NH}_{4} \mathrm{OH}$ dilué, $\rightarrow p \mathrm{H} 6,6$

$\underset{\text { Précipité Filtrat }}{\downarrow} \underset{\downarrow}{\downarrow}$

$+\underset{\sim 0,7}{\left(\mathrm{NH}_{4}\right)_{2} \mathrm{SO}_{4} \rightarrow} \rightarrow$ et concentration de la solution par évaporation

Cristaux d' $\alpha$-lactalbumine

(lavés par $\left(\mathrm{NH}_{4}\right)_{2} \mathrm{SO}_{4}$ à 0,7 de saturation)

(1963) est-elle intéressante. Elle présente les mêmes caractéristiques que celles mises au point par le même auteur pour la $\alpha$-lactoglobuline (cf. § 1132).

d) Conclusion

L'a-lactalbumine, par son faible poids moléculaire (16 000 d'après Gordon et Ziegler, 1955 et Wetlaufer, 1961) et sa facilité de préparation sous forme cristalline, semble une protéine intéressante pour entreprendre une étude de structure. De part et d'autre du point isoélectrique, Klostergaard et Pasternak (1957) ont observé par électrophorèse de Tiselius une certaine hétérogénéité de l' $\alpha$-lactalbumine cristallisée dépendant du tampon utilisé et de la concentration en protéines.

\section{C. - La sérum albumine}

Elle ne représente qu'une faible proportion, 4,7 p, 100, des protéines du lactosérum (tabl. 1) et elle a les mêmes propriétés que la sérum albumine du sang (tabl. 4) dont elle ne diffère que par 
son comportement électrophorétique. Sa mobilité électrophorétique à $p \mathrm{H} \mathrm{8,4} \mathrm{est} \mathrm{légèrement} \mathrm{plus} \mathrm{forte} \mathrm{et} \mathrm{elle} \mathrm{montre,} \mathrm{en} \mathrm{tampon} \mathrm{acétate}$ $p H 4,0, \Gamma / 2=0,02$, une hétérogénéité plus marquée que la sérum albumine du sang d'après Polis, Shmukler et Custer (1950). Coulson et Stevens (1950) ont trouvé par contre une identité complète entre les deux protéines en ce qui concerne leurs propriétés antigéniques.

\section{TABLEAU 4}

PROPRIÉTÉS COMPARÉES DE LA SÉRUM ALBUMINE PRÉPAREE A PARTIR DU SANG ET DU LATT DE VACHE

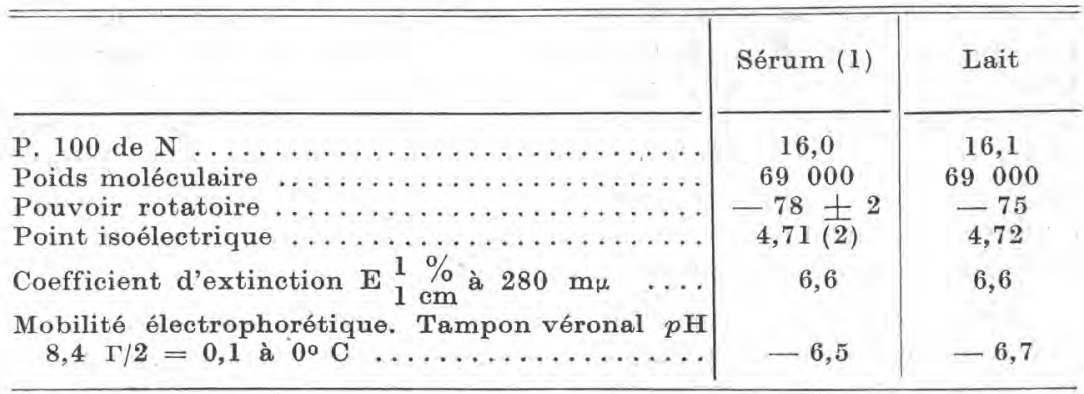

(1) D'après Cohn E. J., Hughes E. C. Jr et Weare J. H., 1947, J. am. chem. Soc., 69, 1753.

(2) D'après Longsworth L. G. et JACoвsen C. F., 1949. J. phys. and coll. Chem., 53, 126.

\section{a) Séparation}

Polis, Shmukler et Custer (1950) ont appliqué au lait la méthode employée pour séparer la sérum albumine du sang qui consiste à effectuer des fractionnements répétés des protéines solubles par le sulfate d'ammonium $(2,4$ à $3,4 \mathrm{M})$ à différents $p H$ puis par l'alcool (10 à $40 \mathrm{p} .100)$ à basse température. La cristallisation est amorcée par addition finale de sulfate d'ammonium en présence de caprylate.

\section{b) Identification}

La sérum albumine correspond au pic no 7 observé par Larson et Rolleri (1955) en électrophorèse de Tiselius et de mobilité - 6,7 en tampon véronal $p \mathrm{H} 8,4$ (fig. 1). Quelques propriétés ont été rassemblées dans le tableau 4. Elle correspond au composant $\gamma$ de Pedersen (1936) de constante de sédimentation $\mathrm{S}_{20}=7,1$.

c) Dosage

Il n'existe pas de méthode de dosage spécifique et sa concentration ne nous est connue que par électrophorèse selon Tiselius (tabl. 1). 


\section{II. - Les immuno-globulines}

D'après Rowland (1938)a, les globulines du lait correspondent aux protéines du lactosérum qui sont précipitées par le sulfate de magnésium saturé. Comme les globulines du sérum sanguin, elles ont été fractionnées par dialyse en euglobulines et pseudoglobulines. Elles sont constituées essentiellement d'immuno-globulines mises facilement en évidence par leur propriété de réagir avec une substance antigénique bien définie.

\section{A. - Séparation}

La méthode de séparation des globulines du sérum sanguin a été appliquée par E. L. Smith (1946) au lait. Elle consiste essentiellement à effectuer une précipitation fractionnée des protéines solubles du lait par le sulfate d'ammonium en ne retenant que celles solubles entre 30 et 40 p. 100 de solution saturée de sulfate d'ammonium. Après dialyse contre l'eau distillée on sépare les euglobulines insolubles (environ $110 \mathrm{mg} / \mathrm{l}$ de lait écrémé) des pseudoglobulines solubles (environ $60 \mathrm{mg} / \mathrm{l}$ de lait écrémé).

Les euglobulines et pseudoglobulines obtenues sont homogènes par électrophorèse en phase liquide, mais ne sont pas homogènes par ultracentrifugation. Kenyon, Anderson et Jenness (1959) ont proposé l'emploi du rivanol (2 ethoxy-6,9-diaminoacridine lactate) mais sans réussir à préparer des produits qui soient homogènes par électrophorèse.

\section{B. - Identification}

Les immuno-globulines sont caractérisées par leur faible mobilité électrophorétique en tampon véronal $p \mathrm{H} 8,6 \Gamma / 2=0,1, \mu=-1,8$ pour les euglobulines et $\mu=-2,0$ pour les pseudoglobulines (Murthy et Whitney, 1958). Elles ne contiennent pas de phosphore mais des sucres : 2,5 à 2,9 p. 100 d'hexose et 1,3 p. 100 d'hexosamine (Smith, 1946). 76 à 90 p. 100 des immuno-globulines sédimentent en un pic de coefficient de sédimentation $\mathrm{S}_{20}=7$ (P. M. 180000$)$ ), les autres immuno-globulines sédimentent en deux pics $\left(S_{20}=10\right.$ et $\left.\mathrm{S}_{20}=20\right)$. Elles peuvent être identifiées en mettant à profit leur propriété de réagir comme anticorps avec un certain antigène, réaction spécifique qui peut se traduire par une précipitation, une agglutination, la fixation du complément, etc.

\section{C. - Dosage}

D'après la méthode d'Aschaffenburg et Drewry (1959) la teneur en globulines est obtenue en retranchant des protéines non caséines, les protéoses peptones et les albumines. Cela revient à faire une différence entre deux chiffres élevés ce qui réduit considérablement la précision avec laquelle la teneur en globulines du lait peut être connue. La méthode de Rowland $(1938) b$ conduit à une détermi- 
nation directe des globulines, les chiffres que cet auteur obtient sont manifestement trop élevés quand on les compare à ceux obtenus par électrophorèse (Aschaffenburg et Drewry, 1959).

A l'aide de diverses réactions immunologiques il est possible de déterminer la présence de certaines immuno-globulines spécifiques et même de les doser. Lorsque les animaux sont atteints de Brucellose, il suffit de mélanger une solution d'antigènes colorés et le lait : au bout d'un certain temps les anticorps contenus dans le lait agglutinent l'antigène qui remonte à la surface sous forme d'un disque coloré ("Ring test »). Certaines substances du lait appelées lacténines exercent vis-à-vis de plusieurs microorganismes tels que Str. cremoris, Str. lactis ou Str. pyogenes une action inhibitrice. Certaines de ces substances sont constituées par des anticorps ou agglutinines présents dans le lait. La concentration du lait en agglutinines de ce type est évaluée en déterminant la dilution maximum du lait qui produit encore une agglutination ou une inhibition de la croissance de l'organisme-test (Portmann et Auclair, 1959)a.

La détermination de la concentration en anticorps conduit à des mesures relatives et ne donne pas habituellement la quantité en $\mathrm{mg}$ d'anticorps présents. La concentration est exprimée le plus souvent en effet par une dilution limite au-delà de laquelle la réaction spécifique ne se produit plus, elle dépend assez largement du type de la réaction spécifique employée.

Le colostrum, qui correspond à la secrétion des tout premiers jours suivants la mise bas, est très concentré en protéines (4 fois plus que le lait normal) et près de la moitié de ces protéines sont constituées par des anticorps ou immuno-globulines. Cette concentration élevée en anticorps fait du colostrum une source de choix pour les préparer. Récemment Montreuil et al. (1963) ont de nouveau mis à profit cette propriété pour fractionner et étudier les diverses immuno-globulines. Ces anticorps jouent un rôle important dans l'immunité qu'acquiert le veau nouveau-né car, contrairement à d'autres espèces animales, les anticorps de la mère ne traversent pas le placenta. Les immuno-globulines ingérées par le jeune animal sont rapidement absorbées par les parois du tube digestif. Cette absorption est facilitée par la présence d'un inhibiteur de la trypsine contenu dans le colostrum qui évite la protéolyse de ces anticorps avant leur absorption (Laskowski et Laskowki, 1951).

\section{III. - Les protéoses peptones}

Les protéoses peptones ont été définies par Rowland (1937) comme les protéines du lactosérum non précipitées à $p \mathrm{H} \mathrm{4,6}$ après chauffage à $95^{\circ} \mathrm{C}$ pendant $30 \mathrm{mn}$ mais précipitées par l'acide trichloracétique à 10 p. 100 . Elles ont été appelées ainsi en raison de leur solubilité dans l'acide trichloracétique à 4 p. 100 comme le 
sont les premiers produits de dégradation des protéines. De nombreux travaux en particulier ceux de Rowland (1937), Larson et Rolleri (1955), Aschaffenburg et Drewry (1959) ont montré qu'elles préexistent dans le lait non chauffé et que par suite elles ne semblent pas être le résultat de dégradation d'autres protéines. Elles constituent un groupe complexe et malgré un certain nombre de tentatives il n'a pas été possible de préparer des fractions homogènes. Toutes les protéoses peptones préparées possèdent en commun les propriétés d'être des glycoprotéines et d'être sensibles à l'action de la présure (Brunner et Thompson, 1961). Nous avons réuni dans ce chapitre les différentes préparations suivantes : protéoses peptones d'après Rowland (1938), protéose $\sigma$ d'après Aschaffenburg (1946), constituant 5 d'après Jenness (1959) et la fraction protéique mineure de Weinstein, Duncan et Trout (1951).

\section{A. - Séparation}

La méthode de Rowland (1938)a, reprise par Brunner et Thompson (1961) consiste à précipiter la caséine à $p H 4,6$ après chauffage du lait à $95^{\circ} \mathrm{C}$ pendant $30 \mathrm{mn}$. Le filtrat est dialysé et lyophilisé.

La protéose $\sigma$ préparée selon Aschaffenburg (1946) représente les protéoses peptones selon Rowland insolubles dans le sulfate d'ammonium à demi saturation. La préparation de la fraction protéique mineure de Weinstein, Duncan et Trout (1951) est assez analogue à celle de la protéose $\sigma$ mais la caséine est éliminée sous forme de paracaséinate de calcium insoluble après action de la présure. La préparation du constituant 5 est résumée dans le tableau 5 .

Aucune de ces préparations ne sont homogènes par ultracentrifugation ou par électrophorèse (tabl. 6).

\section{B. - Identification}

Les analyses faites par Brunner et Thompson (1961) et Thompson et Brunner (1959) sont assez significatives de ce groupe de glycoprotéines et elles sont indiquées dans le tableau 6. Les protéoses peptones étudiées contiennent toutes du phosphore, des sucres et pour certaines d'entre elles on a trouvé de l'acide sialique en proportions analogues à celles observées pour les glycoprotéines du sang, ce qui fait penser à une commune origine. Un certain pourcentage, non négligeable, de ces protéines sont solubles dans l'acide trichloracétique à 12 p. 100 et le pourcentage très élevé obtenu avec la fraction protéique mineure s'explique si l'on considère qu'elle doit être fortement contaminée par les produits de dégradation des caséines par la présure solubles dans l'acide trichloracétique à 12 p. 100. Après action de la présure, la proportion de protéine soluble dans l'acide trichloracétique à 12 p. 100 augmente pour chacune des fractions de protéoses peptones préparées (Brunner et Thompson, 1961). Cette augmentation est de 13 p. 100 de la protéine 


\section{TABLEAU 5}

PRÉPARATION DU CONSTITUANT 5 A PARTIR DU LAIT DE VACHE NORMAL D'APRÈS JENNESS (1959) ADAPTÉE PAR BRUNNER ET THOMPSON (1961)

$$
\begin{gathered}
\text { Lait écrémé } \\
\mid+=\mathrm{NaCl} \rightarrow \text { saturation } \\
\mid \theta=40^{\circ} \mathrm{C} \\
\downarrow--\downarrow \downarrow
\end{gathered}
$$

Filtrat Précipité (caséines + protéoses peptones)

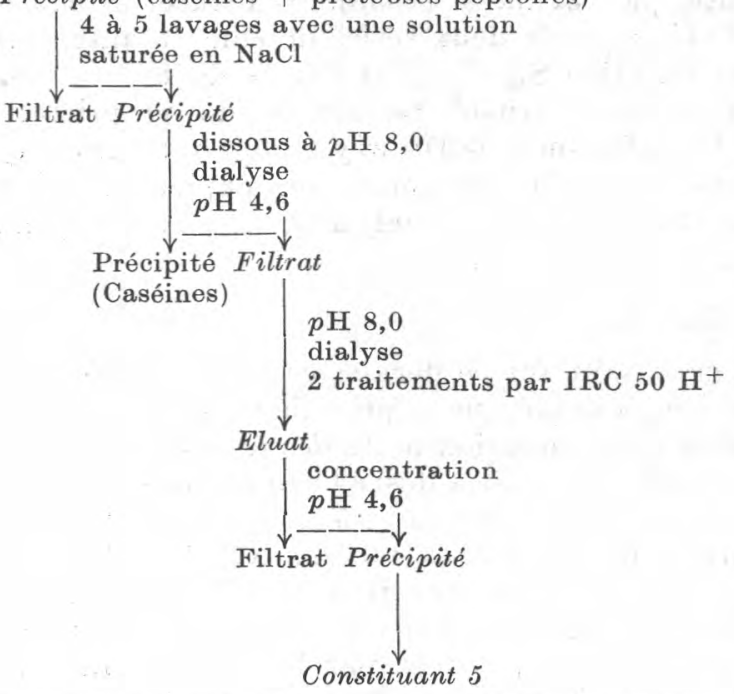

\begin{tabular}{|c|c|c|c|c|c|c|c|}
\hline n & $\begin{array}{l}N \\
(\%)\end{array}$ & $\begin{array}{l}P \\
(\%)\end{array}$ & $\begin{array}{c}\text { Hexose } \\
(\%)\end{array}$ & 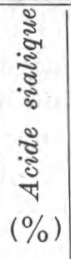 & 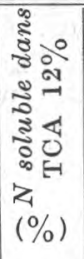 & $\begin{array}{c}\mathrm{S}_{20} \\
\text { U. Sved. }\end{array}$ & 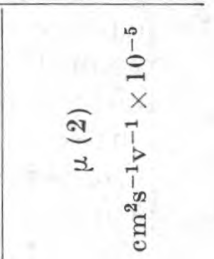 \\
\hline $\begin{array}{l}\text { Protéoses peptones } \\
\text { (Rowland) } \ldots \ldots \\
\text { Protéose } \sigma \ldots \ldots \ldots \\
\text { Constituant } 5 \ldots \ldots \ldots \\
\text { Fraction protéique } \\
\quad \text { mineure } \ldots \ldots \ldots \ldots\end{array}$ & $\begin{array}{l}13,7-13,9 \\
13,7-13,9 \\
12,6 \\
10,2-10,4\end{array}$ & $\begin{array}{l}1,1 \\
0,88 \\
1,5 \\
0,6\end{array}$ & $\left|\begin{array}{l}2,9-4,3 \\
2,8 \\
0,92 \\
3,46-6,94\end{array}\right|$ & 3,6 & $\begin{array}{r}19,36 \\
3,98 \\
6,67 \\
41,24\end{array}$ & $\begin{array}{l}2,64-0,77 \\
2,86-0,83 \\
5,88-0,88 \\
2,83-0,84\end{array}$ & $\begin{array}{c}6,3-3,5-2,0 \\
5,8-3,9-2,0 \\
7,2-5,4-4,4-2,8 \\
\\
5,3-4,5-3,1\end{array}$ \\
\hline
\end{tabular}

TABLEAU 6

COMPOSITION DES DIFFÉRENTES PROTÉOSES-PEPTONES DU LAIT DE VACHE NORMAL (1)

(1) D'après BrunNer et Thompson (1961) et Thompson et BrunNer (1959).

(2) Mobilité électrophorique (branche descendante) en tampon véronal $p H \mathrm{H}, 6$, le constituant le plus important en quantité est indiqué en chiffres italiques. 
initiale pour la protéose peptone, de 1 p. 100 pour la protéose $\sigma$ de 0,6 p. 100 pour le constituant 5 et 5,5 p. 100 pour la fraction. protéique mineure. L'examen électrophorétique révèle la présence dans ces préparations d'un constituant commun de mobilité 3,5 à 4,5 selon les fractions (tabl, 6) et qui correspond sensiblement au pic $\mathrm{n}^{\circ} 5$ observé au cours de l'électrophorèse du lactosérum (fig. 1) d'où le nom de constituant 5 donné à la préparation correspondante par Jenness (1959). L'ultracentrifugation montre en outre l'existence de deux séries de constituants, l'un de coefficient de sédimentation $S_{20}=0,8$ et l'autre de $S_{20}=2,8$. La protéose $\sigma$ d'Aschaffenburg (1946) est douée de propriétés tensio-actives. Enfin Aschaffenburg et Drewry (1959) ont signalé que les protéoses peptones, après électrophorèse sur papier, se coloraient en jaune avec le bleu de bromophénol, mais elles sont cependant difficiles à déceler,

\section{C. - Dosage}

En se basant sur ce dernier caractère de coloration, les mêmes auteurs ont indiqué que le procédé de Rowland (1938)a ne conduisait pas à une séparation nette des protéoses peptones. La méthode de Rowland consistait à doser l'azote soluble à $p H 4,7$ après chauffage à l'ébullition 5-10 mn et à déduire l'azote soluble dans l'acide trichloracétique à 12 p. 100 (ou N.P.N.). Les résultats obtenus par cette méthode étaient toujours plus élevés que ceux obtenus par électrophorèse de Larson et Rolleri (1955) où les protéoses peptones sont représentées par les constituants 3,5 et 8 (fig. 1). D'après Aschaffenburg et Drewry (1959) les protéoses peptones précipitent quand on ajoute $12 \mathrm{~g}$ de sulfate de sodium à $100 \mathrm{ml}$ de filtrat de lait de vache précipité à $p H 4$ 4, De l'azote non caséine on déduit l'azote du surnageant pour calculer l'azote des protéoses peptones précipitées. Cette méthode a le mérite de fournir des résultats proches de l'analyse électrophorétique. En effet si Aschaffenburg et Drewry (1959) identifient 6 protéoses peptones, l'une correspondrait au constituant 5 (fig. 1) et les 5 autres au constituant 3 , la somme des constituants 3 et 5 se rapproche des quantités de protéoses peptones déterminées par Aschaffenburg et Drewry (1959) (tabl. 1).

\section{IV. - Les protéines mineures}

Nous avons groupé sous ce terme toutes les autres protéines du lait dont la concentration n'est pas suffisante pour être décelée par électrophorèse selon Tiselius en tampon véronal $p \mathrm{H} 8,6 \Gamma / 2=0,1$. Elles comprennent essentiellement la protéine rouge, la lactolline, les protéines de la membrane des globules gras et les enzymes du lait.

\section{A. - La protéine rouge ou lactotransferrine}

Après les premières tentatives en vue de séparer du lait une 
protéine rouge, Groves (1960) réussit à préparer celle-ci dans un excellent état de pureté en utilisant une propriété particulière : l'adsorption sur le précipité de caséine au point isoélectrique.

\section{1) Séparation}

La technique employée par Groves (1960) a été résumée dans le tableau 7 ; cette séparation se termine par une chromatographie sur échangeur d'ions (D.E.A.E. cellulose). Comme d'après Gordon, Ziegler et Basch (1962) il semble que la protéine rouge existe également dans le lait sous une forme incolore non combinée à du fer, ces derniers auteurs ont suggéré d'ajouter au lait du fer pour augmenter les rendements en protéine rouge.

\section{2) Identification}

La préparation de protéine rouge ou lactotransferrine selon Groves (1960) est homogène à l'électrophorèse selon Tiselius, son

\section{TABLEAU 7}

PRÉPARATION DE LA PROTÉINE ROUGE A PARTIR DU LAIT DE VACHE NORMAL D'APRÈS GROVES (1960)

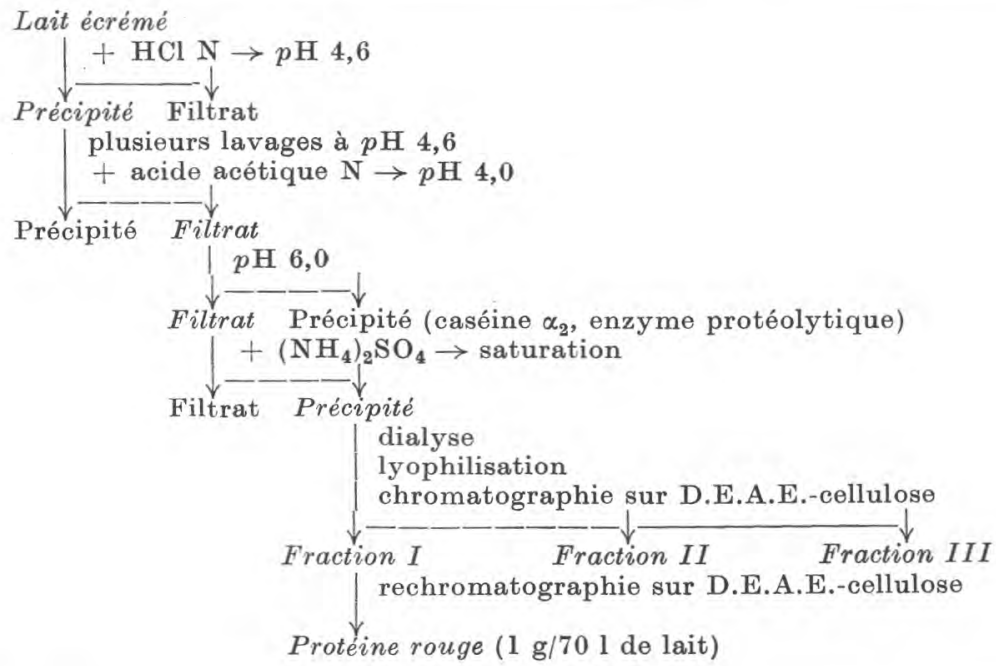

point isoélectrique est de $7,8(\Gamma / 2=0,1)$ et ne donne qu'un seul pic par ultracentrifugation en tampon phosphate $p \mathrm{H} 7\left(\mathrm{~S}_{20}=5,2\right)$. Groves a déterminé un poids moléculaire de 86 100. La protéine rouge contient deux atomes de Fe par molécule et présente un maximum assez large d'absorption vers $470 \mathrm{~m} \mu$ à $p \mathrm{H}$ neutre. Il est possible de dissocier à $p \mathrm{H}$ acide et d'une manière réversible le 
complexe Fe-protéine. Elle appartient au groupe des glycoprotéines: phosphorées avec une teneur en phosphore de 0,22-0,25 p. 100, en hexose de 4,7 p. 100, en hexosamine de 2,3 p. 100 et en acide sialique de 0,3 p. 100. Elle diffère de la transferrine du sang aussi bien par sa composition en acides aminés que par son comportement par chromatographie, électrophorèse et ultracentrifugation (Gordon, Groves et Basch, 1963). Blanc, Bujard et Mauron (1963) ont également donné sa composition en acides aminés en la comparant à la lactotransferrine humaine.

\section{3) Dosage}

Il n'existe pas de dosage spécifique dans le lait. Sous forme de préparation purifiée il est possible de mettre à profit le maximum d'absorption observé de 465 à $470 \mathrm{~m} \mu$. Groves (1960) a déterminé

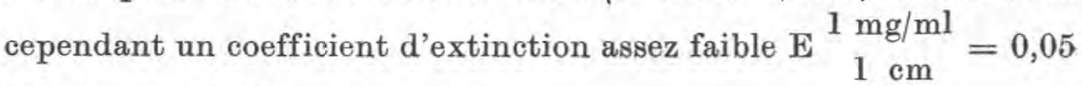
à $465 \mathrm{~m} \mu$ et à $p \mathrm{H}$ neutre.

\section{B. - La Iactolline}

Comme la protéine rouge, la lactolline est adsorbée sur le précipité de caséine à $p H 4,7$. Signalée au début comme la protéine cristallisée par Groves (1960), elle n'a été que récemment étudiée (Groves, Basch et Gordon, 1963).

\section{1) Séparation}

La technique d'isolement de Groves, Basch et Gordon (1963) est celle de Groves (1960) pour séparer la protéine rouge (tabl. 7) en y incluant un fractionnement supplémentaire par le sulfate d'ammonium (40 à 60 p. 100 de saturation). Les cristaux recueillis directement après chromatographie sur D.E.A.E.-cellulose (la lactolline est éluée immédiatement après la protéine rouge) sont dissous à $p \mathrm{H} \mathrm{5,0}$ et recristallisés deux fois après ajustement du $p \mathrm{H}$ à 6,2 et à 8,2 . Le rendement est de 0,6 à $1,6 \mathrm{mg}$ de lactolline par litre de lait écrémé. Il est accru en partant du colostrum : 5,9 mg/litre.

\section{2) Identification}

Elle présente la propriété de cristalliser facilement à $p \mathrm{H}$ neutre d'où son premier nom (Groves, 1960). Elle présente un minimum de solubilité à $p \mathrm{H} 8$ et son point isoélectrique est situé vers $p \mathrm{H}$ 7,1 . Son poids moléculaire est de $42900 \pm 5000\left(\mathrm{~S}_{20}, \omega=3,21\right.$ à $p H 5$, tampon acétate $\Gamma / 2=0,1)$. Elle ne contient pas de méthionine, peu d'alanine et cystine mais une forte proportion d'acides aminés aromatiques.

\section{3) Dosage}

Il n'existe pas de dosage spécifique dans le lait. Le coefficient 
d'extinction à $280 \mathrm{~m} \mu, \mathrm{E}^{1 \mathrm{mg} / \mathrm{ml}}=1,65$ à $p \mathrm{H} 5$ (Groves, Basch et Gordon, 1963) peut être utilisé pour déterminer la concentration d'une solution de lactolline cristallisée.

\section{C. - Les protéines de la membrane des globules gras}

Quoiqu'elles aient des propriétés assez voisines de celles des protéoses peptones, leurs caractéristiques d'ultracentrifugation, leur propriété de former des complexes avec les lipides (et par suite d'être disposées à la surface des globules gras) nous conduit à les ranger dans une catégorie spéciale.

TABLEAU 8

PRÉPARATION DES PROTÉINES DE LA MEMBRANE DES GLOBULES GRAS A PARTIR DU LAIT DE VACHE NORMAL

D'APRÈS HERALD ET BRUNNER (1957) ET BRUNNER ET THOMPSON (1961)

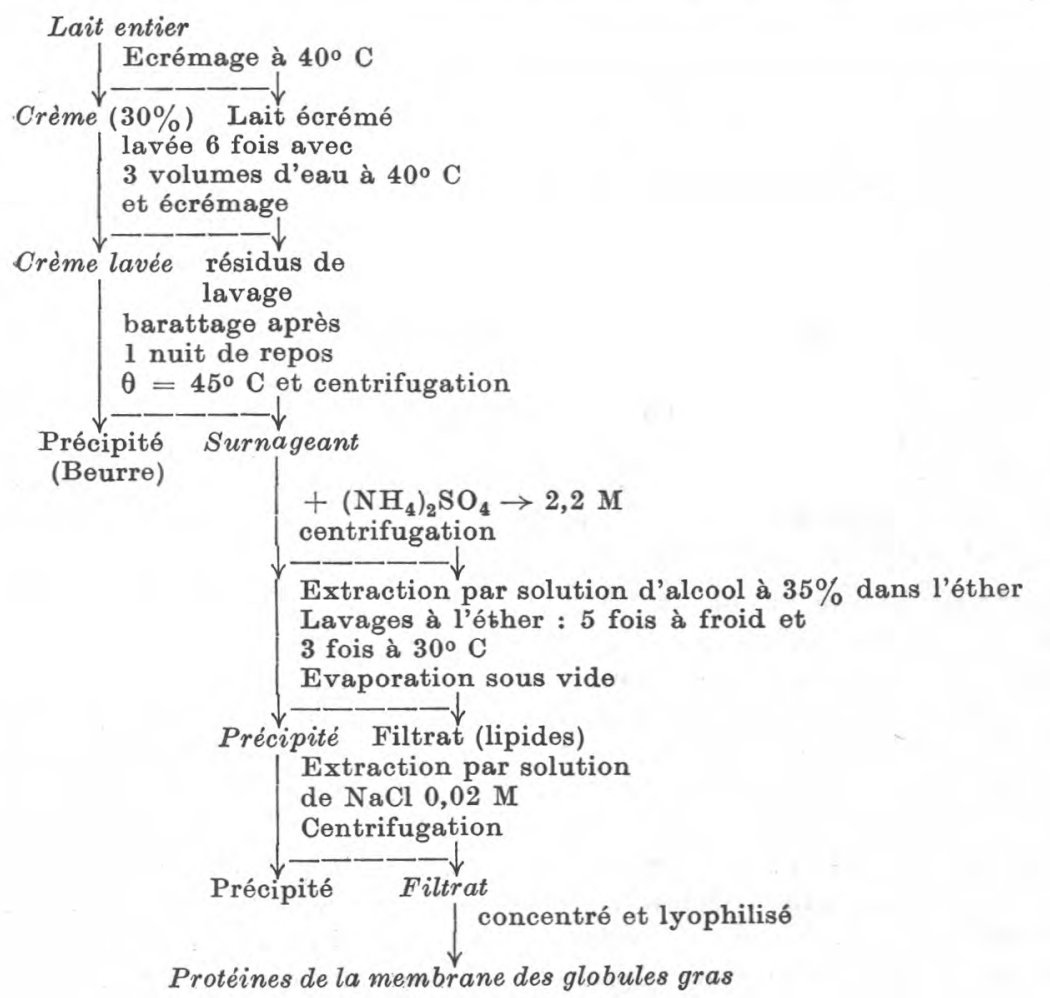




\section{1) Séparation}

Nous avons reporté dans le tableau 8 la méthode de séparation. la plus couramment utilisée actuellement : celle d'Herald et Brunner (1957). Morton (1954) a également décrit une méthode conduisant à la séparation d'un complexe lipoprotéique attribué aux microsomes du lait provenant des cellules de la glande mammaire.

\section{2) Identification}

Ce sont des glycoprotéines (2,69 à 4,04 p. 100 d'hexose d'après Brunner et Thompson (1961) qui contiennent du phosphore (0,68 p. 100).

Une proportion relativement élevée est soluble dans l'acide trichloracétique à $12 \mathrm{p} .100$ (environ $6 \mathrm{p}$. 100) mais elles ne sont pas sensibles à l'action de la présure même après chauffage. Par électrophorèse selon Tiselius elles se montrent constituées par deux fractions, l'une de mobilité $\mu=4,7(96,5 \mathrm{p}$. 100) et l'autre de mobilité $\mu=2,3(3,5$ p. 100$)$ en tampon véronal $p H$ 8,6. Par ultracentrifugation elles sédimentent sous la forme de deux constituants de coefficient de sédimentation $\mathrm{S}_{20}=17,6$ et 9,05 en tampon véronal $p H$ H,6 $\Gamma / 2=0,1$. La valeur très élevée de ces deux coefficients de sédimentation les différencie des protéoses peptones.

\section{3) Dosage}

Il n'existe pas de méthode de dosage de ces protéines. Etant liées aux lipides sous forme de complexe lipoprotéique, elles ne sont pas des constituants normaux du lait écrémé.

\section{D. - Les enzymes du lait}

Ils sont nombreux, mais leurs origines sont le plus souvent assez mal définies car elles peuvent être fort différentes : ils peuvent en effet être secrétés par la glande mammaire, ou provenir du plasma sanguin, ou provenir des leucocytes ou encore des bactéries présentes dans le lait.

Cette dernière éventualité est souvent éliminée en utilisant du lait obtenu par traite aseptique de vaches dont la mamelle n'héberge aucun germe microbien. Quelques-uns de ces enzymes ont été préparés à l'état cristallisé. La destruction de certains par la chaleur est utilisée comme test d'une pasteurisation convenable. Etant donné leur faible importance, quantitativement et qualitativement, nous nous contenterons d'en faire ici une revue rapide, inspirée en particulier d'une mise au point faite par Whitney (1958) en considérant plus spécialement leur séparation, leur identification et leur dosage. Nous les avons classés dans l'ordre où ils sont le mieux étudiés et connus et en ne retenant que ceux normalement présents dans le lait. 


\section{1) Le xanthine oxydase}

Son nom provient de sa propriété de transformer la xanthine en acide urique. Préparée sous forme cristallisée par Avis, Bergel et Bray (1955), elle catalyse l'oxydation du diphosphopyridine nucléotide réduit (DPNH) en utilisant différents accepteurs d'électrons : oxygène, bleu de méthylène, cytochrome c etc... Elle est constituée, dans le rapport moléculaire $1 / 2 / 1,3-1,5 / 8$, de protéine-flavine adénine dinucléotide-Mo-Fe pour un poids moléculaire d'environ $300000\left(\mathrm{~S}_{20}=11,4\right)$ (Avis et al., 1956). Elle présente une large bande d'absorption à $450 \mathrm{~m} \mu$ correspondant à sa couleur brun rouge, ainsi que deux autres bandes d'absorption à $350 \mathrm{~m} \mu$ et surtout à $275 \mathrm{~m} \mu$. Greenbank (1954) a mis au point une méthode de dosage basée sur la réduction du bleu de méthylène par l'hypoxanthine et il a trouvé $160 \mathrm{mg}$ environ de xanthine oxydase par litre de lait. La xanthine oxydase est souvent associée à la membrane des globules gras.

\section{2) La lactoperoxydase}

Polis et Shmukler (1953) la préparent à partir du lactosérum présure par précipitation fractionnée à l'aide du sulfate d'ammonium et chromatographie sur colonne de phosphate de calcium. La cristallisation de l'enzyme est obtenue à partir d'une solution 2,2 M de phosphate dipotassique. Elle peut être préparée sous une forme hautement purifiée mais non cristallisée selon un procédé relativement simple d'après Morrisson, Hamilton et Stotz (1957). Il comporte essentiellement plusieurs passages du lactosérum présure sur colonne échangeuse d'ions IRC 50 (XE 64). La lactoperoxydase est identifiée grâce à la bande d'absorption qu'elle possède à $412 \mathrm{~m} \mu$. Le groupement prosthétique est constitué par un hème avec un atome de fer et Polis et Shmukler (1953) ont déterminé un poids moléculaire de 81000 .

On peut la doser soit en suivant son activité enzymatique par la méthode au gaïacol par exemple de Mealhy (1954) ou bien en déterminant son activité inhibitrice sur la croissance de Str. pyogenes d'après la méthode d'Auclair et Hirsch (1953) d'estimation de la lacténine $\mathrm{L}_{2}$ dont l'identité avec la lactoperoxydase a été démontrée par Portmann et Auclair (1959). D'après les résultats de Polis et Shmukler (1953) il est possible de calculer la teneur du lait en lactoperoxydase soit environ $30 \mathrm{mg} /$ litre (Whitney, 1958).

La lactoperoxydase a donné lieu à des études théoriques de la réaction enzyme-substrat, en particulier celles de Chance (1950) et de Theorell et al.

\section{3) La phosphatase alcaline}

C'est également un constituant normal du lait présent à l'interface sérum-globules gras. Morton (1953) l'a préparée à partir de la crème : celle-ci est barattée, les lipoprotéines contenues dans le 
babeurre sont dissociées par traitement avec le butanol et les protéines ainsi séparées des lipides sont fractionnées par le sulfate d'ammonium. Morton a ainsi obtenu un enzyme hautement purifié mais non cristallisé, homogène à l'électrophorèse et ne possédant qu'une activité de phosphomonoestérase.

Le dosage de la phosphatase dans le lait est pratiqué en utilisant comme substrats : le phénylphosphate disodique (Kay et Graham, 1935 et Aschaffenburg et Neave, 1939) et le paranitrophényl phosphate, en titrant le phénol libéré par le réactif de Folin et Ciocalteu par exemple, ou le $\beta$-glycérophosphate de soude en déterminant le phosphore libéré (Jacquet et Saingt, 1952).

Le fait qu'elle soit dénaturée plus lentement par la chaleur que ne sont détruits les microorganismes pathogènes non sporulés a été mis à profit pour vérifier la pasteurisation correcte du lait.

D'autres phosphatases ont été signalées dans le lait : une phosphodiestérase, deux pyrophosphatases (Guittoneau, Chevalier et Jarrousse, 1944) et deux phosphomonœstérases acides dont l'une serait plus résistante à la destruction par la chaleur que la phosphatase alcaline (Jacquet et Saingt, 1952).

\section{4) Les lipases du lait}

Il existe toute une série de lipases naturelles dans le lait capables d'hydrolyser un certain nombre de substrats : beurre, huiles végétales, tributyrine, etc. Certaines de ces lipases sont actives spontanément dans le lait - en particulier celles qui s'adsorbent sur la membrane des globules gras au cours du refroidissement du lait -, d'autres ont besoin d'une activation par agitation ou homogénéisation et elles sont le plus souvent associées à la fraction caséine (Tarassuk et Frankel, 1957).

Quelques essais de séparation des lipases ont été tentés par Tarassuk et Frankel (1957) et Harper, Gould et Badami (1956) sans obtenir de préparations homogènes. D'autres tentatives plus récentes semblent avoir été plus fructueuses. Montgomery et Forster (1961) ont purifié l'estérase B en l'adsorbant sur l'hydroxyde de magnésium $\mathrm{Mg}(\mathrm{OH})_{2}$. Chandan et Shahani (1963) ont légèrement modifié le procédé de Desnuelle (1961) et l'ont appliqué aux boues d'écrémeuses qu'ils ont extraites à l'acétone, à l'eau, puis après précipitation fractionnée par le sulfate d'ammonium et chromatographie sur Sephadex G 50 ils ont obtenu une préparation homogène à l'électrophorèse sur gel d'amidon d'un poids moléculaire d'environ 7000 . Cet enzyme purifié hydrolyse les graisses du lait et la tributyrine.

Le dosage des lipases se fait soit d'après la mesure de la vitesse d'hydrolyse d'esters de référence : tween 20 , tributyrine, butyrate de méthyl, phényl propionate, etc. au $p \mathrm{H}$ stat ou en mesurant le $\mathrm{CO}_{2}$ dégagé à partir d'un tampon bicarbonate au Warburg ; 
soit d'après le dosage des acides gras libérés séparés au préalable sur colonne de silicagel (Harper, Schwartz et El Hagarawy, 1956). La teneur en lipase est exprimée par Frankel et Tarassuk (1956) en unités arbitraires d'après la mesure de la quantité de soude nécessaire pour neutraliser l'acide formé lors de l'hydrolyse par la lipase de la liaison ester, ou encore en micromoles d'acides gras libérés/100 $\mathrm{ml}$ de mélange réagissant $/ \mathrm{h} / \mathrm{mg}$ de protéine comme il est recommandé dans le Rapport de la Commission sur les Enzymes (1961).

On a distingué 3 lipases alcalines ( $p \mathrm{H}$ optimum 7 à 7,9 ) et 4 lipases acides ( $p \mathrm{H}$ optimum 5,4 à 6,3$)$. L'une des lipases alcalines appartient d'après Forster, Bendixen et Montgomery (1959) au groupe des estérases B qui hydrolysent à la fois les esters aromatiques et aliphatiques et sont inhibés par les composés organophosphoriques. Les mêmes auteurs distinguent également dans le lait une activité estérase $\mathrm{A}$, spécifique des esters aromatiques, non inhibée par les composés organophosphoriques et probablement une activité estérase $\mathrm{C}$ spécifique des esters de choline et inhibée par la physostigmine. La teneur en estérase A augmente beaucoup dans les laits de mammites (Marquardt et Forster, 1962).

Les lipases jouent un rôle important dans la lipolyse spontanée des matières grasses (goût de rance) du lait et des produits laitiers (beurre, fromages) (Bachman, 1959).

Plusieurs revues générales ont été publiées concernant les lipases du lait; la plus récente est celle de Chandan et Shahani (1964).

5) Amylase

Le lait possède la propriété d'hydrolyser l'amidon. Guy et Jenness (1958) ont obtenu une préparation fortement concentrée par précipitation du lactosérum par le sulfate d'ammonium à 43 p. 100 de saturation. Il semble que cette préparation ait un seul $p \mathrm{H}$ optimum d'activité à 7,4 .

L'activité de cette amylase est mesurée en suivant la variation de viscosité de l'amidon, la quantité de sucres réducteurs libérés ou la quantité de l'amidon non hydrolysé par le réactif à l'iode.

6) Protéase

Warner et Polis (1945) ont montré que presque toute l'activité protéolytique du lait était précipitée avec la caséine. Ils ont obtenu une préparation enrichie 150 fois en cet enzyme par précipitation à $p H$ 4,5 d'une solution de caséine protéolysée et dialysée et fractionnement du filtrat par le sulfate d'ammonium.

Cet enzyme de propriétés voisines de la trypsine a un optimum d'activité à $p H$ 9,2 et résiste à l'action de la chaleur. Par fractionnement de la caséine à l'alcool et à l'urée, il se trouve dans la fraction 
caséine $\alpha$ (Hipp et $a l ., 1952)$ et il peut en être éliminé par précipitation fractionnée à l'alcool à $p \mathrm{H} 6,0$.

7) Catalase.

Il semble qu'elle soit un enzyme naturel du lait d'après Reid (1931) mais il y a toujours une forte proportionnalité entre la quantité de catalase présente dans le lait et le nombre de bactéries ou de leucocytes présents. Aucun essai de séparation n'a été entrepris.

D'autres enzymes ont été signalés dans le lait sans que leur origine soit bien établie telle que l'aldolase qui hydrolyse le fructose 1-6-diphosphate. Polis et Shmukler (1950) ont montré qu'elle était concentrée dans la crème et ils ont amorcé un début de fractionnement par les sels neutres.

Enfin Dills et Nelson (1942) ont séparé du lactosérum une protéine contenant 0,19 p. 100 de cuivre non dialysable à $p \mathrm{H} 6,5$ ou céruloplasmine. Elle serait à l'origine du cuivre présent dans le lait à l'état non-dialysable.

\section{Summary}

A review on the separation, identification and evaluation of whey proteins of cow's milk.

\section{RÉFÉRENCES BIBLIOGRAPHIQUES}

R. Aschaffenburg. Surface activity and proteins of milk. J. Dairy Res., $1946,14,316-329$.

R. Aschaffenburg, J. Drewry. Occurrence of different beta-lactoglobulins in cow's milk. Nature, 1955, 176, 218-219.

R. Aschaffenburg, J. Drewry. Improved method for the preparation of crystalline $\beta$-lactoglobulin and $\alpha$-lactalbumin from cow's milk. Biochem. $J$., 1957 a, 65. 273-277.

R. Aschaffenburg, J. Drewry. Genetics of the $\beta$-lactoglobulins of cow's milk. Nature, $1957 \mathrm{~b}, 180,376-378$.

R. Aschaffenburg, J. Drewry. New procedure for the routine determination of the various non casein proteins of milk. XV e Cong. intern. Lait., 1959, 3, seet. 5, 1631-1637.

R. Aschaffenburg, F. K. Neave. A rapid phosphatase test. J. Dairy Res., $1939,10,485-497$.

J. E. Auclair, A. Hirsch. The inhibition of microorganisms by raw milk. J. Dairy Res., 1953, 20, 45-49.

P. G. Avis, F. Bercel, R. C. Bray. Cellular constituents. The chemistry of xanthine oxydase. Part $I$. The preparation of a crystalline xanthine oxydase from cow's milk. J. Chem. Soc., 1955, 77, 1100-1105.

P. G. Avis, F. Bercel, R. C. Bray, W. F. James, K. V. Shooter. Cellular constituents. The chemistry of xanthine oxydase. Part. II. The homogeneity of crystalline metalloflavoprotein fractions. J. Chem. Soc., 1956, 78, 1212-1219.

M. Bachmann. Der Einfluss von Mileh mit Erhöhter Lipaseaktivität auf die Käsereifung. $X V^{\mathrm{e}}$ Congr. intern. Lait., 1959, 2, 712-715. 
K. Bell. One dimensional starch-gel electrophoreisis of Bovine skim milk. Nature, 1962, 195, 705-706.

B. BLANC, E. BUJARD, J. MAURON. The amino acid composition of human and bovine lactotransferrine Experientia, 1963, 19, 299-301.

J. R. BRUNNER, M. P. THOMPson. Characteristics of several minor-protein fractions isolated from Bovine milk. J. Dairy Sci., 1961, 44, 1224-1237.

R. K. Cannan, A. H. Palmer, A. C. Kibrick. The hydrogen ion dissociation curve of $\beta$-lactoglobulin. J. Biol. Chem., 1942, 142, 803-822.

R. Cecil, A. G. OGSTON. The sedimentation constant, diffusion constant and molecular weight of lactoglobulin. Biochem. J., 1949, 44, 33 .

B. Change. The properties of the enzyme-substrate compounds of lactoperoxydase. J. am. chem. Soc., 1950, 72, 1577-1583.

R. C. Chandan, K. M. Shahant. Purification and characterization of milk lipase. I. Purification. J. Dairy Sci., 1963, 46, 275-283.

R. C. Chandan, K. M. Shahani Milk Lipases. A Review. J. Dairy Sci., $1964,47,471-480$.

E. J. Coulson, H. Stevens. The serological relationship of bovine whey albumin to serum albumin. $J$. Biol. Chem., 1950, 187, 355-363.

C. Crowther, H. Raistrick. A comparative study of the proteins of the colostrum and milk of the cow and their relation to serum proteins. Biochem. J,, 1916, 10, 434-451.

M. Dautrevaux. Isolement de l' $\alpha$-lactalbumine du lait de vache, Ann. Biol. Anim. Bioch. Biophys., 1963, 3, numéro hors série, 125-127.

P. Desnuelle. Pancreatic lipase. Adv. Enzymology, 1961, 23, 129.

W. L. Drlls, J. M. Nelson. Isolation of a copper bearing protein from cow's milk. J. Am. chem Soc., 1942, 64, 1616.

T. L. Forster, H. A. Bendixen, M. W. Montgomery. Some esterases of cow's milk. J. Dairy Sci., 1959, 42, 1903-1912.

E. N. Frankel, N. P. Tarrassuk. The specificity of milk lipase. I. Determination of the lipolytic activity in milk toward milk fat and simpler esters. J. Dairy Sci., 1956, 39, 1506-1516.

W. G. Gordon, M. L. Groves, J. J. Basch. Bovine milk "red protein " amino acid composition and comparison with blood transferrine. Biochemistry, 1963, 2, 817-820.

W. G. Gordon, W. F. Semmetr. Isolation of erystalline $\alpha$-lactalbumin from milk. J. am. chem. Soc., 1953, 75, 328-330.

W. G. Gordon, W. F. Semmett, J. Ziegler. Crystalline $\alpha$-lactalbumin : an improved method for its isolation. Sulfur distribution. $J$. amer. Chem. Soc., 1954, 76, 287.

W. G. Gordon, J. Ziegler. Amino acid composition of crystalline- $\alpha$ lactalbumin. Arch. Biochem. Biophys., 1955, 57, 80-86.

W. G. GORDON, J. ZIEgler, J. J. BAsCH. Isolation of an iron binding protein from cow's milk. Biochim. Biophys. Acta, 1962, 60, 410-411.

G. R. Greenbank. The xanthine oxydase (Schardinger's enzyme) content of dairy products and its inhibition by heat. J. Dairy Sci., 1954, 37, 644.

M. L. Groves. The isolation of a red protein from milk. J.am. Chem. Soc., $1960,82,3345-3350$.

M. L. Groves, J. J. Basch, W. G. Gordon. Isolation characterization and amino acid composition of a now crystalline protein, lactollin, from milk. Biochemistry, 1963, 2, 814-817.

E. von Gugler, M. Bein, G. von Muralt. Uber immunoelektrophoretische Untersuchungen an Kuhmilehproteinen. Schweiz. Mediz. Wochen, 1959, 89, $1172-1176$.

G. Guittonneau, R. Chevalier, H. Jarrousse. Sur la présence dans le lait de vache de deux pyrophosphatases accumulables dans le beurre et le babeurre, C. R. Acad. Sci., 1944, 218, 1006.

E. J. GuY, R. JENNEss. Separation, concentration and properties of alphaamylase from cow's milk. $J$. Dairy Sci., 41, 1958, 13-27.

L. A. Hanson. Immunological Analysis of Bovine Blood, Serum and Milk. Comparative analysis of human milk and human blood plasma by 
means of diffusion in gel methods. Experientia, 1959, 15, 471-475.

W. J. HARper, I. A. Gould, M. BADAMI. Separation of the major components of the milk lipase system by supercentrifugation. $J$. Dairy Sci., 1956, 39, 910 .

W. J. Harper, D. P. SchWartz, I. S. El Hagarawy. A rapid silica-gel method for measuring free fatty acids in milk. J. Dairy Sci., 1956, $39,46$.

C. T. Herald, J. R. Brunner. The fat globule membrane of normal eow's milk. The isolation and characteristics of two membranes protein fraction. J. Dairy Sci., 1957, 40, 948-956.

N. J. Hipp, M. L. Groves, J. H. Custer, T. L, McMenkin. Separation of $\alpha$ - $\beta$ - and $\gamma$-caseins. J. Dairy Sci., 1952, 35, 272-281.

P. H. von Hrpped, D. F. WAUGH. Casein-Monomers and Polymers. J. amer. Chem. Soc., 1955, 77, 4311-4319.

J. JACQUET, O. SAINGT, Les phosphomonoesterases du lait de vache, $C . R$. Soc. biol., Paris, 1952, 146, 1515-1518.

R. Jenness. Characterization of milk serum protein component $5 . J$. Dairy Sci., 1959, 42, 895.

R. Jenness, B. L. Larson, T. L. McMeerin, A. M. Swanson, C. H. WhitNAH, R. MCL. Whitnex. Nomenclature of the proteins of bovine milk. J. Dairy Sci, 1956, 39, 536-541.

H. D. Kay, W. R. GrahaM. The phosphatase test for pasteurised milk. J. Dairy Res., 1935, 6, 191-203.

A. J. KENYON, R. K. ANDERSON, R. JenNeSs. Isolation of immune globulins from milk and colostrum with Rivanol. J. Dairy Sci., 1959, 42, 1233-1234.

H. Klostergaard, R. A. Pasternak. Electrophoresis and ultracentrifuge studies of milk proteins. II. $\alpha$-lactalbumin. $J$. amer. Chem. Soc., 1957, 79, $5674-5676$.

B. L. Larson, D. C. Gillespie. Origin of the major specific proteins in milk. J. Biol. Chem., 1957, 227, 565-573.

B. L. Larson, E. C. Hageman. Determination of $\alpha$-lactalbumin in complex systems. J. Dairy Sci, 1963, 46, 14-18.

B. L. Larson, R. Jenness. Identification of $\alpha$-lactalbumin in the electrophoretic pattern of milk serum proteins. J. Dairy Sci., 1955, 38, 313-315.

B. L. Larson, G. D. Rolleri. Heat denaturation of the specific serum proteins in milk. J. Dairy Sci., 1955, 38, 351-360.

B. L. Larson, J. M. Twarog. Determination of $\beta$-lactoglobulin in complex systems by a simple immunological procedure. J. Dairy Sci., 1961, 44, $1843-1856$.

M. LASKowSKI Jr, M. LASkowski. Crystalline trypsin inhibitor from colostrum. J. Biol. Chem., 1951, 190, 563.

Linderstrom-LANG, C. F. JACoBSEN, 1941. The contraction accompanying enzymatic breakdown of proteins. C. R. trav. Lab. Carlsberg, 1941, 24, série Chim., 1.

S. Lissitzky, M. Rolland, S. Lasky. Oxydation de la ribonucléase et de l' $\alpha$-lactalbumine par la polyphénoloxydase de champignon. Bioch. Biophys. Acta, 1960, 39, 379-380.

R. R. MARquardt, T. L. Forster. Arylesterase activity of bovine milk as related to incidence of mastitis. J. Dairy Sci., 1962, 45, 653 .

T. L. McMegrin. In H. Neurath and K. Bailex, "The Proteins i. Vol. II, part. A, 389-434, Academic Press, New York, 1954.

A. C. Mealmy. The assay of catalases and peroxydases. In Grick, Met. Biochem. Analysis, 1, 386-408. Intersec. Pub. New York, 1954.

G. Mocquot, C. Alais, R. Chevalier. Etude sur les défauts de coagulation du lait par la présure. Ann. Technol. agric., 1954, 1, 1-44.

M. W. Montgomerey, T. L. Forster, 1961. Partial purification of the B-esterase of bovine milk. J. Dairy Sci, 1961, 44, 721.

J. Montreuil, N. Anthony, J. Descamps, N. Duquesne. Etude des glyeoprotéides du lait de femme et de vache. Ann. Biol. anim. Bioch, Biophys., 1963, 3, numéro hors série, 129-133. 
M. Morrison, H. B. Hamiton, E. Stotz. The isolation and purification of lactoperoxydase by ion exhange chromatography. J. Biol. Chem,, 1957, 228, 767-776.

R. K. Morton. Alkaline phosphatase of milk. II. Purification of the enzyme. Biochem. J., 1953, 55, 795-800.

R. K. Morton. The lipoprotein particles in cow's milk. Biochem. J., 1954, 57, 231-237.

G. J. MüLder. Zusammensetzung von Fibrin, Albumin, Leinzucker, Leucin, s. u. w. Ann. Pharm., 1938, 28, 73.

G. K. Murthy, R. Mel. Whitnex. A comparison of some of the chemical and physical properties of $\gamma$-casein and immune globulins of milk. J. Dairy Sci., 1958, 41, 1-12.

A. G. Ogston, M. P. Tomвs. The heterogeneity of bovine $\beta$-lactoglobulin. Biochem. J., 1957, 66, 399-403.

J. Oudin. L'analyse immunochimique qualitative. Méthode par diffusion des antigènes au sein de l'immunsérum précipitant gélosé. Ann. Inst. Pasteur, 1948, 75, 30-51.

A. H. PALmer. The preparation of a crystalline globulin from the albumin fraction of cow's milk. J. Biol. Chem., 1934, 104, 359-372.

K. O. Pedersen. Ultracentrifugal and electrophoretic studies on the milk proteins. I. Introduction and preliminary results with fractions from skim milk. Biochem. J., $1936 a$, 30, 948-960.

K. O. Pedersen. Ultracentrifugal and electrophoretic studies on the milk proteins. II. The lactoglobulin of Palmer. Biochem. J., 30, 961-970, $1936 \mathrm{~b}$.

K. A. Pinz, E. W. Davie, J. E. Folk, J. A. Gladner. B-lactoglobulins A and B. I. Chromatographic separation and amino acid eomposition. J. Biol. Chem., 1961, 236, 2912-2916.

B. D. Polis, H. W. Shmukler. Aldolase in bovine milk. J. Dairy Sci., 1950, 33, 619-622.

B. D. Polis, H. W. Sнмukrer. Crystalline lactoperoxydase. I. Isolation by displacement chromatography. II. Physicochemical and enzymatic properties. J. Biol. Chem. 1953, 201, 475-500.

B. D. Polis, H. W. Shmukler, S. H. Custer. Isolation of a erystalline albumin from milk. J. Biol. Chem., 1950, 187, 349-354.

A. Portmann, J. E. Auclair. Relation entre les lactosérum et les agglutinines du lait de vache Ann. Inst. Pasteur, 1959 a, 97, 590-596.

A. Portmann, J. E. Auclair. Relation entre la lacténine $\mathrm{L}_{2}$ et la lactoperoxydase. Le Lait, $1950 \mathrm{~b}, 39,147-158$.

Rapport de la Commission sur les Enzymes de l'Union Internationale de Biochimie. Pergamon Press, New York, N. Y., 1961, p. 104.

K. REID. Untersuchungen über den katalasegehalt der kuhmilch. Milch. Forsch., 1931, 11, 590-599.

G. D. Rolleri, B. L. Larson, R. W. Touchberry. Protein production in the bovine breed and individual variations in the protein constituents of milk. J. Dairy Sci., 1956, 39, 1683-1689.

S. J. Rowland. The soluble protein fraction of milk. J. Dairy Res., 1937, 8, 6-14.

S. J. RowLAND. The precipitation of the proteins in milk. I. Casein. II. Total proteins. III. Globulins. IV. Albumin and proteose peptone. J. Dairy Res., 1938 a, 9, 30-41.

S. J. RowLAND. The determination of the nitrogen distribution in milk. J. Dairy Res., 1938 b, 9, 42-46.

E. L. Sмгтн. Isolation and properties of immune lactoglobulins from bovine whey. J. Biol. Chem., 1946, 165, 665-676.

M. Sorensen, S. P. L. Sorensen. The Proteins whey. C. R. Trav. Lab. Carlsberg, Ser. Chim, 1939, 23, 55.

N. F. Tarassuk, E. N. Frankel. The specificity of milk lipase. IV. Partition of the lipase system in milk. J. Dairy Sci., 1957, 40, 418-430. 
M. P. Thompson, J. R. Brunner. The carbohydrates of some glycoproteins of bovine milk. J. Dairy Sci., 1959, 42, 369-370.

J. M. A. Trlley. The chemical and physical properties of bovine $\beta$-lactoglobulin. Dairy Sci. Abstr., 1960, 22, 111-125.

S. N. Timasheff, R. Townend. Molecular interactions in $\beta$-lactoglobulin. $V$. The association of the genetic species of $\beta$-lactoglobulin below the isoelectric point. $J$. amer. chem. Soc., $1961 a, 83,464-469$.

S. N. TrmashefF, R. Townend. Molecular interactions in $\beta$-lactoglobulin. VI. The dissociation of the genetic species of $\beta$-lactoglobulin at acid $p \mathrm{H}^{\prime} \mathrm{s}$. $J$. amer. chem. Soc., 1961 b, 83, 470-473.

R. Townend, C. A. Kiddy, S. N. Timasheff. Molecular interactions in $\beta$-lactoglobulin. VII. The "Hybridization" of $\beta$-lactoglobulins A et B. $J$. amer. Chem. Soc., 1961, 83, 1419-1423.

R. Townend, R. J. Winterbottom, S. N. Timasheff. Molecular Interactions in $\beta$-Lactoglobulin. II. Ultracentrifugal and Electrophoretic Studies of the Association of $\beta$-Lactoglobulin below its, isoelectric point. $J$. amer. chem. Soc., 1960, 82, 3161-3168.

R. C. WAKE, R. L. BALDWIN. Analysis of casein fractions by zone electrophoresis in concentrated urea. Bioch. Biophys. Acta, 1961, 47, 225-239.

R. C. WARner, E. Polis. On the presence of a proteolytic enzymein casein. J. amer. Chem. Soc., 1945, 67, 529.

B. R. Weinstein, C. W. Duncan, G. M. Trout. The solar activated flavor of homogeneized milk. IV. Isolation and characterization of a whey constituent capable of producing the solar activated flavor. J. Dairy Sci., 1951. 34, 570-576.

D. B. Wetla UFER. Osmometry and general characterization of $\alpha$-lactalbumin. C. R. Trav. Lab. Carlsberg, 1961, 32, 125-138.

R. Mel. Whitney. The minor proteins of bovine milk. J. Dairy Sci., 1958, 41, 1303-1323.

R. C. Wright, J. Tramer. Factors influencing the activity of cheese starters. The role of milk peroxydase. $J$. Dairy Res., 1958, 25, 104-118.

\title{
REVUE
}

\section{L'INDUSTRIE LAITIËRE DANS LE MONDE}

\author{
par \\ G. GENIN \\ Ingénieur EPCI
}

\section{Réfrigération du lait}

\section{ITALIE}

Des études ont été récemment entreprises à l'Université de Milan sur la conservation et le transport du lait après réfrigération. Cette nouvelle technique permettrait de stabiliser le lait pendant plusieurs semaines et même plusieurs mois, de réduire les frais de transport, et même de supprimer tout risque d'adultération par addition d'eau. La température de stockage ne doit pas s'élever au-dessus de 10 à $15^{\circ} \mathrm{C}$. 